\title{
PROBLEMATIZANDO CONCEPÇÕES DE PROFESSORES DE CIÊNCIAS SOBRE EDUCAÇÃO AMBIENTAL E CIDADANIA CRÍTICA: UMA PARCERIA ENTRE O ENGENHEIRO AMBIENTAL E A ESCOLA
}

\author{
Paulo Sérgio Araújo da Silva ${ }^{1}$ \\ Lucas de Jesus Soares da Cruz ${ }^{2}$
}

Resumo: $O$ trabalho investiga as concepções de professores sobre Educação Ambiental e de Cidadania Crítica, e as relações que estas podem estabelecer para pensar a formação do cidadão crítico. O objetivo é compreender como pensam os docentes sobre Educação Ambiental e Cidadania Socioambiental Crítica. Por meio de pesquisa qualitativa, buscou-se coletar dados descritivos de onze professores da rede municipal de ensino de Paragominas-PA a partir da utilização de questionário. Os resultados apontam que é preciso romper com algumas ideias preservacionistas, de conscientização e de comportamentos ambientais, se o professor tiver a intenção de formar para a cidadania socioambiental crítica.

Palavras-chave: Educação Ambiental; Formação de Professores; Cidadania.

Abstract: This paper investigates the conceptions of teachers about Environmental Education and Critical Citizenship, and the relations which can be established to think about the education of the critical citizen. The objective is to comprehend the way teachers think about Environmental Education and Socioenvironmental Critical Citizenship. Through qualitative research, we sought to collect descriptive data from eleven teachers from the municipal school system in the city of ParagominasPA through a questionnaire. The results indicate that there is a need to break with some preservationist ideas of awareness and environmental behaviour if the teacher intends to train for critical socioenvironmental citizenship.

Keywords: Environmental Education; Teacher Training; Citizenship.

${ }^{1}$ Universidade do Estado do Pará. E-mail: paulo_a_s@yahoo.com.br, Link para o Lattes: http://lattes.cnpq.br/3919329870924804 :

2Universidade do Estado do Pará. E-mail: lucascruzad@gmail.com, Link para o Lattes: http://lattes.cnpq.br/4514108461453673

Revbea, São Paulo, V. 16, № 2: 488-500, 2021. 


\section{O contexto da investigação e aporte teórico}

O contexto da pesquisa está na interação entre uma parceria de um Engenheiro Ambiental e professores de ciências de uma escola pública, estes últimos foram convidados, pelo primeiro, a participar de um processo formativo, sobre ideias relativas a Educação Ambiental, algo que será melhor detalhado adiante.

É preciso situar a função do Engenheiro Ambiental com a proposta de formação direcionada a professores do ensino básico, pois está em consonância com a sua área de atuação, como é possível verificar no trecho a seguir.

O Engenheiro Ambiental tem por função primordial planejar, gerir e executar ações mitigadoras que minimizem a deterioração da ambiência, de modo a assegurar a preservação da qualidade de vida. Sua formação o habilita a estabelecer estreitos diálogos, tanto para a troca de conhecimentos técnico-científicos e experiências, como no relacionamento com outras profissões tradicionais [...] (PARÁ, Universidade do Estado do Pará, Curso de Engenharia Ambiental, Projeto Político Pedagógico, s/d)

Nesse âmbito, o Engenheiro Ambiental passou a entender que pensar as concepções de professores de ciências sobre Educação Ambiental (EA) requer um resgate do contexto histórico da Educação Ambiental em termos nacionais e internacionais.

Para Guimarães (2003) a questão ambiental ganhou destaque mundial com a realização da Conferência das Nações Unidas sobre o meio ambiente, realizada em Estocolmo, em 1972. Dentre os assuntos discutidos estava em pauta o papel da educação para o meio ambiente.

Em 1977, Conferência Intergovernamental sobre Educação Ambiental, em Tbilisi (na ex-União Soviética).

No Brasil, a EA tardou para chegar oficialmente (PERES et al., 2005). Entretanto, baseado na obra de Leão e Silva (1999), sabe-se que no período em que se começou a debater mundialmente as questões ambientais, como na conferência realizada em Estocolmo, já existia no Brasil a influência das mobilizações que ocorriam na Europa e nos Estados Unidos.

Somente em 1981 foi instituída no Brasil a Política Nacional de Meio Ambiente. Em 1988, a EA pode ser vislumbrada pela primeira vez na Constituição Federal e sugerindo a inserção de temas voltados à questão ambiental em todos os níveis do ensino.

$\mathrm{Na}$ década de 90, a EA teve grande ascensão e espaço para debates, como na Conferência Internacional das Nações Unidas para o Meio Ambiente e Desenvolvimento, realizada no Rio de Janeiro. Nessa mesma década acontece 
o Fórum de Educação Ambiental (1997) e também a I Conferência Nacional de Educação Ambiental (1997).

A partir dos eventos mencionados, vêm à tona propostas de resoluções dos problemas ambientais, impulsionadas também por: mudanças de concepções de meio ambiente, adquiridas pelo homem, e, portanto, a necessidade de reflexão e modificação da sua forma de interação no ambiente ao longo do tempo; a utilização da educação, através da escola, como locus privilegiado na formação do cidadão crítico, inserindo a questão ambiental -a Educação Ambiental- em seu contexto. Para Loureiro (2009), a Educação Ambiental é tratada a partir de uma educação que atua na transformação social, no exercício da cidadania, fortalecendo os sujeitos, superando as dominações capitalistas e promovendo uma compreensão de mundo e de vida em sua complexidade e totalidade.

A Educação Ambiental, a partir dos Parâmetros Curriculares Nacionais é tradada como Tema Transversal associando os problemas ambientais com fatores econômicos, políticos, sociais e históricos, levantando discussões sobre as responsabilidades humanas na perspectiva da superação da crise ambiental (BRASIL, 1998).

Nesse contexto, o professor de ciências pode e/ou deveria ser um educador ambiental, ou seja, aquele que através do ensino também educa para o cuidado com o ambiente. Assim, o professor é um mediador na formação de cidadãos preocupados com o ambiente e suas diversas transformações. Numa sociedade cujos valores estão centrados no "ter" e, portanto, no consumo excessivo, e, no consequente aumento de produção de resíduos diversos, que afeta a qualidade da água, do ar, do solo e a vida das populações, professores preocupados com as pautas socioambientais são cada vez mais necessários. $\mathrm{O}$ que requer destes, concepções contemporâneas de EA que auxiliem na formação de alunos para o exercício da cidadania socioambiental crítica.

Uma vez assumindo como um de seus objetivos a formação de cidadãos críticos, a EA compartilha de muitas ideias presentes no ensino de Ciência, Tecnologia e Sociedade (CTS). Para Santos e Mortimer (2001) o principal objetivo de ensino CTS é o letramento científico e tecnológico para que os alunos possam atuar como cidadãos, tomando decisões e agindo com responsabilidade social. Foi com essa aproximação entre EA e CTS que a formação com os sujeitos investigados foi desenvolvida, tanto pelos estudos de CTS serem amplos com pesquisadores da área de Ensino de Ciências, quanto pela discussão da cidadania nas produções CTS, além da temática ambiental ser recorrente nos estudos CTS. Estes estudos foram inseridos em alguns momentos durante o processo de formação, bem como os PCN -Temas transversais, pois essas leituras continham elementos teóricos, que todo 0 grupo envolvido na pesquisa demostra ter algum conhecimento e se mostraram desejos de se apropriarem de maneira mais consistente dos mesmos.

Assim, a formação de cidadãos tem sido almejada por educadores do ensino de ciências, como Santos e Schenetzler (1998), que nas suas 
proposições entendem o ensino como contribuinte para a formação de indivíduos críticos, e afirmam que ao se discutir ensino de ciências e cidadania, se faz necessário refletir sobre o papel da ciência e da educação na construção da cidadania. Essas reflexões acontecem no contexto onde várias produções científicas foram realizadas, como na área da agricultura, agropecuária, da medicina, da biotecnologia, entre outros, que de certa forma tornou a sociedade dependente da ciência. Esses avanços parecem ser positivos à sociedade, como reflexo, temos a longevidade da população e a comunicação em tempo real em qualquer lugar do mundo. A ciência promoveu 0 desenvolvimento tecnológico, e esse desenvolvimento implicou, também, em avanços na própria ciência. Mas a ciência não tem apenas o seu lado benéfico. É preciso que os alunos percebam que nos bastidores da produção científica perpassam questões econômicas, políticas, e até éticas, que podem determinar a intenção final do trabalho dos cientistas. Assim, é necessário questionar a pretensa e enganosa "neutralidade" científica, através da compreensão das relações Ciência, Tecnologia e Sociedade, ou abordagem CTS.

A interação do ensino de ciências com a abordagem CTS pretende melhorar a compreensão da realidade da sociedade e formar cidadãos críticos no intuito de intervirem como agentes ativos na esfera social. Para tanto, necessitam compreender o ambiente em que vivem para descobrir e tomar decisões alternativas às mazelas da sociedade, pois "o que adiantará ao aluno aprender a nomear rochas e fenômenos geológicos, se não compreender como os recursos naturais têm sido explorados por grandes grupos econômicos, sem muitas vezes se ter o retorno social dessas riquezas, que são de todos?" (SANTOS; SCHNETZLER, 1998, p. 262).

Deste modo, investigar-se concepções de professores sobre Educação Ambiental e de Cidadania Crítica, e as relações que estas podem estabelecer para pensar a formação para cidadania socioambiental crítica. Tem-se como objetivo compreender concepções docentes de Educação Ambiental e de formação do cidadão crítico, e identificar pontos de convergências e divergências com a formação da cidadania socioambiental crítica.

\section{Metodologia}

Por meio de pesquisa qualitativa, busca-se dados descritivos obtidos diretamente pelo pesquisador junto ao sujeito investigado, retratando as perspectivas do participante (LUDKE; ANDRE, 1986). O processo investigado se dá com sujeitos - onze professores de ciências da rede municipal de ensino de Paragominas. $O$ instrumento de coleta de dados é um questionário contendo dez questões abertas e uma direcionada. Para este trabalho foram selecionadas respostas correspondentes a duas questões: "O que é Educação Ambiental?" e "O que é formar o cidadão crítico?". 
A análise dos dados foi qualitativa, suscitando quatro categorias: Preservação, Conscientização, Comportamento, Concepções de Cidadão Crítico.

A coleta de dados foi extraída de três momento de um processo de intervenção de palestras e debates entre professores e um engenheiro ambiental que desenvolve estudos acadêmicos sobre Educação Ambiental. A parceira foi decisiva para evolução de ideias sobre Educação Ambiental. A organização está descrita a seguir

1‥ Momento- questionário (março de 2018)

2 . Momento (maio de 2018) $\mathrm{CH}: 40 \mathrm{~h}$

- Palestras sobre concepções de Educação Ambiental

- Roda de conversa: construção da cidadania crítica e ensino de ciências

- Roda de conversa: construção da cidadania crítica e Educação Ambiental.

- 3‥ Momento ( $\mathrm{CH} 60 \mathrm{~h})$ setembro/outubro de 2018

- Palestras sobre: concepções de Educação Ambiental

- Roda de conversa: Disposição de resíduos sólidos e EA

- Roda de conversa: construção da cidadania socioambiental crítica.

Apresentada a parte metodológica da pesquisa, a seguir apresenta-se, a análise das categorias com as discussões.

\section{Resultados e discussão}

Percebe-se que as respostas dos professores entrevistados seguem três linhas distintas quando são questionados a respeito do significado da EA, sendo elas: preservação, conscientização e comportamento.

Para apresentar as linhas de significado da EA encontradas destacouse falas de alguns sujeitos cuja identidade foi resguardada e substituída por códigos (Pnúmero).

Também nesse tópico será apresentado uma síntese da evolução das concepções de EA, e a discussão sobre as concepções de cidadania crítica. 


\section{Preservacionista}

Segundo Loureiro (2008), o movimento ambientalista com caráter político e ambiental teve início nos anos 80 , devido à grande extração de recursos naturais, aumentando a produção de produtos a serem consumidos objetivando o lucro. Nesse momento a preservação era o objetivo daquele indivíduo que pensava em proteger o meio ambiente.

Nesse sentido, compreendemos que a importância dada a temas socioambientais, com a EA focada na preservação do meio ambiente, como defendido por seis professores (P1, P3, P4, P8, P9, e P11), no primeiro momento do processo formativo, remete ao pensamento oitentista do século $X X$, que definia o meio ambiente como natureza intocada (DIEGUES, 2004). Tais manifestações leva-nos a entender que essa preservação é referente à concepção naturalista de ambiente.

Dessa maneira, o professor reforça o entendimento de que o meio ambiente deve ser tratado como algo intocável, preservado (VIANNA, 2008). Mas como entender assim o ambiente, se o próprio homem precisa interagir com o meio para sobreviver?

A preocupação ambiental que se almeja dos educadores não é da prescrição de certo ou errado, mas de pensar a complexidade ambiental, que perpassa as atividades econômicas locais e globais, as políticas de manejo dos recursos naturais, geração de empregos, e da qualidade de vida da população em termos de divisão de renda e da ocupação de um ambiente adequado à vida em termos ecológicos e sociais, discussões semelhantes também elencadas por Santos e Schnetzler (1998).

A preservação não é a única bandeira que deve ser priorizada. As questões socioambientais e o conceito de Educação Ambiental estão muito além do ato de preservar. Para Leff (2010, p.180) "a Educação Ambiental incorpora os princípios básicos da ecologia e do pensamento complexo; mas não é tão somente um meio de capacitação em novas técnicas e instrumentos para preservar o ambiente e para valorizar os bens e serviços ambientais".

É preciso ter presente que uma preocupação ecológica, no sentido de manter a vida no planeta é necessária. No entanto, os discursos de exploração dos recursos naturais não podem estar alheios, as políticas de preservação e conservação, que estão no papel, e que parecem oferecer alguma margem de segurança (estamos nos referido as que são consensuais por vários atores e/ou organizações sociais), se assim, forem seguidas, mantendo o lucro econômico, mas na mesma medida ganhos sociais. São muitas das infrações ambientais que desconsideram essas políticas na prática, que colocam em perigo biomas, e na mesma proporção o adequado desenvolvimento socioambiental das populações.

Superada a via preservacionista do meio ambiente, é necessário abordar a via da conscientização neste processo de pensar a Educação Ambiental, como abordamos no próximo subtópico.

Revista brasileira educação ambiental 


\section{Conscientização}

A Educação Ambiental não é simplesmente uma questão de conscientização como se seus ideais ambientais pudessem ser transmitidos. Não é desejável uma EA ambiental, na perspectiva da conscientização, para o sujeito, mas com o sujeito. Um dos professores entrevistados (P5) designa a EA como sendo a sensibilização, conscientização da sociedade em respeito ao meio ambiente. Outro (P6) ainda ao falar sobre EA:- "é uma conscientização. É você criar uma consciência crítica". De modo semelhante pensam também alguns professores entrevistados, são dois no primeiro momento, e sete no segundo momento do processo formativo (ver mais detalhes no subtópico Síntese das concepções de EA, presente neste artigo).

É necessário ter presente que nas práticas educacionais a sensibilização sobre problemáticas ambientais é necessária, mas que a conscientização é um processo interno, pessoal, embora não constituído solitariamente. Assim, a conscientização não deve ser o fim da EA, mas a problematização dos valores ambientais (PERES et al., 2005), ou seja, o problemático é a conscientização encerrar-se no processo de desvelamento da realidade e em prescrições de como ser ambientalmente correto, e achar que ela pode ser acomodada nos pensamentos e nos estilos de vida dos sujeitos, e por isso, não avançar na transformação dos valores e atitudes ambientais.

Pelo contrário, a conscientização é construção pelo diálogo ${ }^{3}$, é com o outro que tenho oportunidade de me reconstruir, de assumir entendimentos sobre minha condição humana no mundo. Logo não se pode perder de vista que nesse processo, o sujeito está no controle, a oportunidade de se reconstruir, é dele. As aceitações e/ou negações, construídas de maneira duradoura, mas não necessariamente imutáveis, das análises das problemáticas ambientais e ações desejáveis para mitigá-las, realizadas por cada sujeito, se dá nesse jogo.

Repensada a via da conscientização na EA, aborda-se a seguir a via comportamentalista de EA.

\section{Comportamentalista}

Outros professores demonstraram em suas respostas uma concepção de Educação Ambiental baseada na transmissão de comportamentos aceitáveis ambientalmente: não jogar lixo na rua, economizar água ao tomar banho, não sujar a sala de aula, entre outros.

Muitas vezes, a questão do estímulo defendida no comportamentalismo é rapidamente percebida, como na resposta do professor P2 sobre o que seja a EA: - "É a educação participativa, onde procuramos desenvolver no aluno o estímulo a participar das problemáticas atuais do meio ambiente, se comportando de forma correta." (P2). Nesse caso, a concepção e a

\footnotetext{
${ }^{3}$ Freire (1998) faz uma ampla discussão sobre o assunto.
} 
metodologia em EA que P2 se apropria são baseadas no estímulo que o aluno deve receber pelo professor, para assim, absorver o conhecimento necessário sobre a importância e cuidados com o ambiente. Muitas vezes os alunos se comportam de acordo com a expectativa do professor para agradá-lo - e com isso obter uma gratificação afetiva imediata - do que por acreditarem nas razões daquele comportamento (CARVALHO, 2008).

Assim, faz-se necessário haver a intenção de uma EA que não se resuma somente no comportamento do indivíduo, como entendem alguns professores, pois tal comportamento mecaniza e extingue a verdadeira intenção de se obter uma preocupação ambiental. Logo, é necessário formar cidadãos que tenham atitudes ambientais coerentes, baseadas na realidade a qual se vive hoje, tendo em mente, que um dia, os recursos vastamente extraídos da natureza não se renovarão. Que isto faça parte da cultura do indivíduo, e que desde cedo saiba os motivos essenciais do porquê se viver em um planeta com habitantes comprometidos com o ambiente, que não sejam pautados apenas em "bons comportamentos". De fato, o comprometimento do cidadão com a responsabilidade social (SANTOS; SCHNETZLER, 1998), implica também o cuidado com o ambiente.

Descontruída a via comportamentalista, neste subtópico, bem como as vias preservacionistas e de conscientização nos subtópicos anteriores, apresenta-se, a síntese processo formativo, a seguir.

\section{Síntese das concepções de EA}

A Figura 1 abaixo, indica a evolução de concepções sobre os três momentos de formação em Educação Ambiental a que os sujeitos investigados foram expostos.

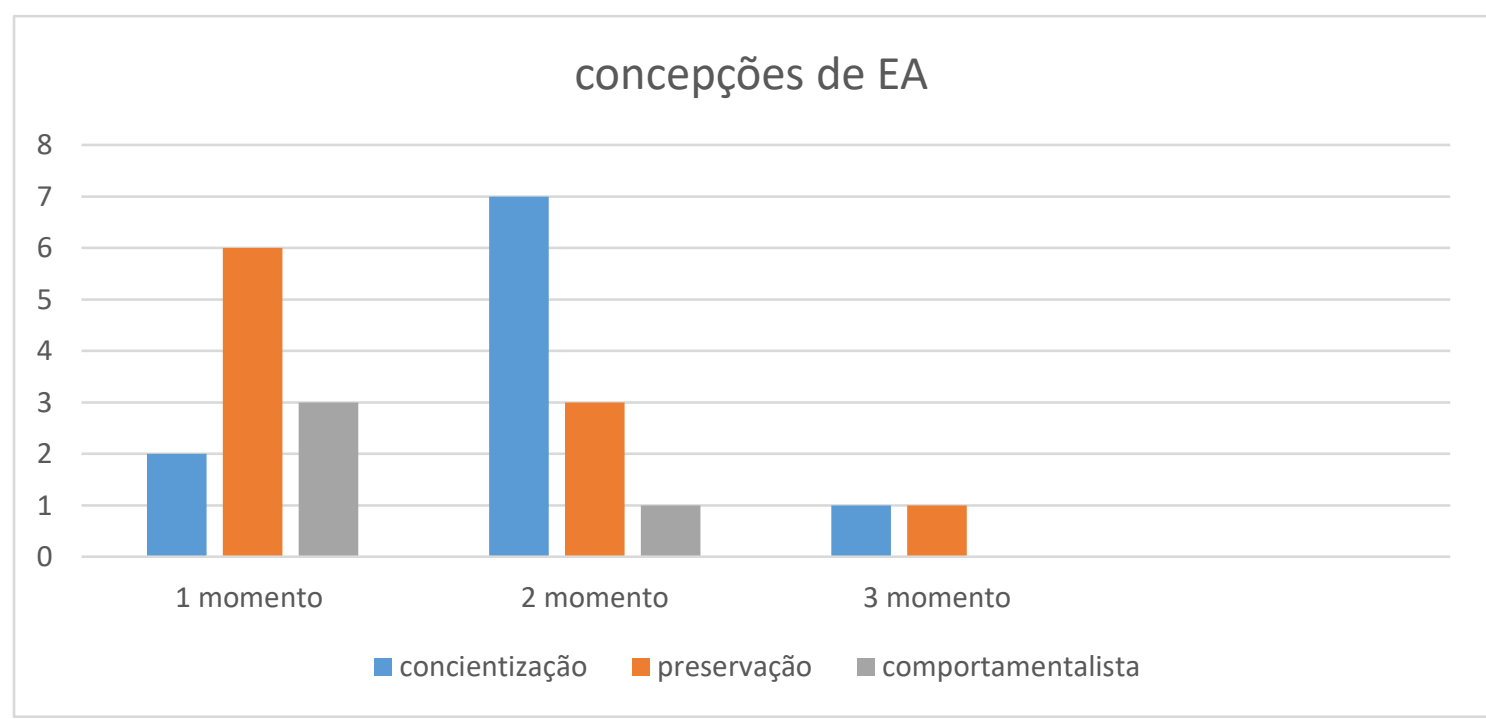

Figura 1: evolução das concepções de EA dos sujeitos investigados.

Fonte: os autores. 
No primeiro momento realizado em março de 2018, 6 professores expuseram concepções de EA como preservação, 2 como conscientização e 3 como comportamentalista. Após a primeira intervenção formativa 7 apresentaram concepções como conscientização, 3 como preservação, 1 como comportamentalista, a transição para mais de $50 \%$ para as concepções de conscientização, se deram em grande medida a fortes intervenções dos palestrantes em oposição as ideias primordialmente preservacionistas e comportamentalistas.

Assim para o formador, o importante no terceiro momento seria uma intervenção para desnaturalizar a ideia de EA como conscientização. E fazer com que prevalece a EA como ato político, e como reflexão de sujeitos, que no debate das questões ambientais, constroem olhares, multi, interdisciplinares, para manutenção digna da vida no planeta Terra. Intenções que parecem ter sido alcançadas como veremos a seguir.

Após a segunda intervenção: 1 como conscientização, 1 comportamentalista, os outros noves 9 assimilaram a Educação Ambiental como prática educativa que busca a transformação de valores e conhecimentos ambientais que promovam a dignidade da vida no planeta neste momento e nas próximas gerações.

Apresentadas as análises e discussão em torno das concepções de EA, como anunciado anteriormente, aborde-se a seguir o levantamento sobre o cidadão crítico.

\section{Concepção de Cidadão Crítico}

A EA é um ato político que se dá, obviamente, com intenções. Ora, uma das intenções da educação no século XXI é a formação de cidadãos críticos, que serão responsáveis por pensarem em possíveis soluções das problemáticas enfrentadas hoje pela sociedade, implicando em tomadas de decisões.Tal formação pressupõe que os educandos estejam preparados para exercerem sua cidadania plena, que não é apenas a busca dos seus direitos com a realização dos seus deveres, mas também o próprio questionamento desses direitos e deveres, para que os mesmos tomem decisões capazes de transformar o mundo para melhor.

De acordo com Brasil (1998), a finalidade de trabalhar a EA é contribuir na formação de cidadãos conscientes que decidam e atuem na sua realidade socioambiental, contribuindo com o bem-estar individual e coletivo.

Para atender a demanda da educação existente no século $X X I$, que pauta como objetivo a formação de cidadãos críticos e que influenciem nas decisões socioambientais de maneira direta, como afirmam os PCN, é que foi modificado também o perfil do professor, haja vista que ele é o principal difusor, fomentador, agente instigante que fará com que o aluno ponha em ação as suas ideias, contribuindo com a sociedade. Espera-se que esse professor 
tenha uma concepção de cidadão crítico condizente com a formação de sujeitos pensantes e atuantes nas mudanças da estrutura da sociedade.

A partir dessas informações, a concepção de cidadania crítica dos professores entrevistados corresponde a uma visão coerente acerca do que é proposto na atualidade. P1 e P2, por exemplo, acredita que deve dar subsídios para que seu aluno avalie e questione as diversas situações em que estiver envolvido, utilizando seu próprio ponto de vista. Além disso, P2 coloca em destaque que a criticidade de seu aluno deve ser utilizada na tomada de decisões tanto individual, quanto social, e assim sucessivamente. Visão essa almejada por Santos e Schnetzeler (1998).

De modo geral, a maioria dos sujeitos (ver Figura 2) consegue visualizar que é responsável pela formação do cidadão crítico, e que esse cidadão consiste em um ser com capacidade de pensar de forma "independente" sobre as várias situações socioambientais que possam surgir no meio em que vive, e assim tomar decisões diante de problemas que atingem o coletivo.

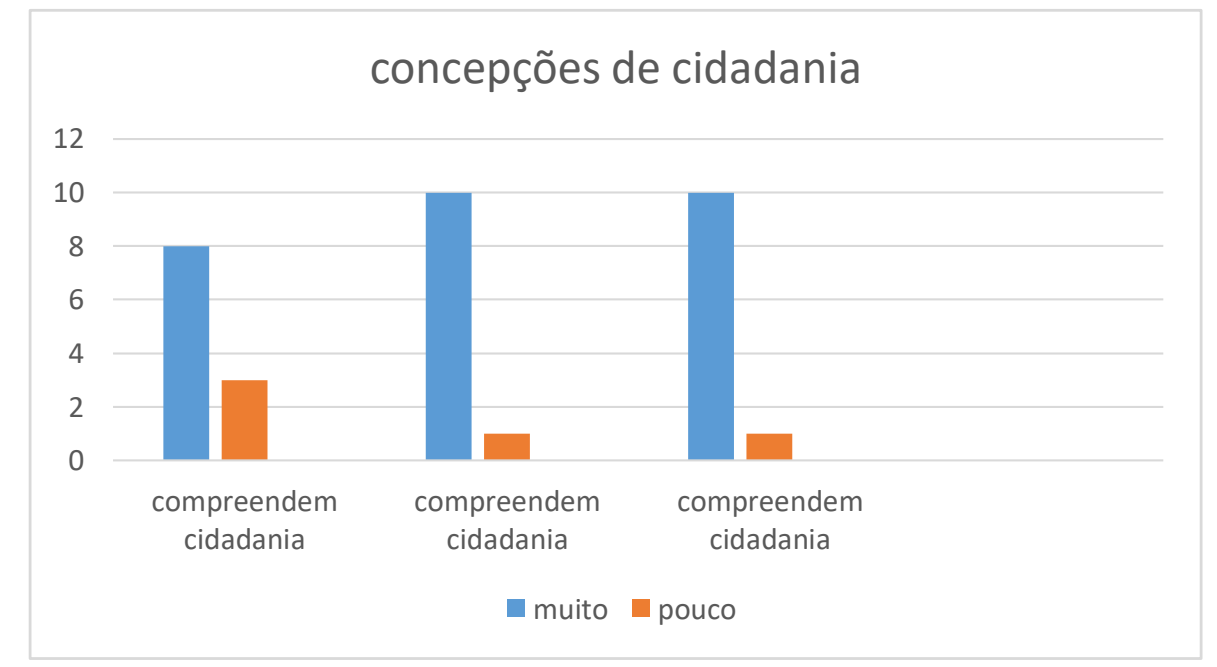

Figura 2: sujeitos investigados que dizem compreender cidadania em cada momento de formação.

Fonte: os autores.

Ainda que a literatura em EA e as diretrizes educacionais apontem por um novo perfil de educação pautado na formação do cidadão crítico, em que o indivíduo possa tomar decisões no meio cultural, político, econômico, como afirma Brasil (1998), não era possível as estes professores desenvolverem a cidadania socioambiental crítica, uma vez que tramitavam em suas concepções de Educação Ambiental ideias preservacionistas, de conscientização, e de comportamentos ambientais a serem adquiridos, no primeiro e no segundo momento do processo formativo, algo que mudou significante no terceiro momento. 
A cidadania socioambiental crítica se apropria de direitos e deveres ambientais constituídos socialmente, e os põe num processo de verificação, ou seja, se suas contribuições caminham na perspectiva da solidariedade, na defesa das condições de vida digna aos seres vivos, e de maneiras adequadas de ocupação e exploração do ambiente, e ainda dos seus contributos para novas gerações. E assim, direcionadas para a tomada de decisão sobre as problemáticas ambientais apresentadas, buscando optar pelas melhores formas de interação com o ambiente.

Retomando a discussão para a formação docente. Ao escrever sobre meio ambiente e formação de professores Penteado (1997) diz que uma coisa é ler e ficar informado sobre o meio ambiente, outra coisa é ler, ficar informado e observá-lo diretamente, analisando como as relações o permeiam e o exploram, obtendo com outros indivíduos informações sobre as relações mantidas com o ambiente em que vivem, apreendendo como a sociedade lida com ele. Para Saheb e Assinelli-Luz (2006) a EA leva à escola a oportunidade de trabalhar com questões que ditam sobre o cotidiano, na vida e nas relações com todos os seres vivos, mas isso só ocorrerá à medida que o professor possibilitar outras condições de aprendizado que não àquela tradicional, caracterizada pela transmissão-recepção do conhecimento.

E nós, por nossa vez afirmamos que, é decididamente importante propor parcerias de formação docente, para reconstrução do saber e fazer docente nas escolas, reconstruir saberes relativos a EA, é sobremaneira relevante para pesquisadores e professores da escola básica, é um aprendizado para ambos.

\section{Conclusões}

A importância do processo formativo proposto pelo Engenheiro Ambiental, foi no sentido de estabelecer diálogos na solução de questões interdisciplinares, o que possibilitou compreensão da Educação Ambiental como projeto de sociedade, para além de atos individuais.

Neste sentido, desenvolver a cidadania socioambiental crítica é contribuir para a formação de sujeitos capazes de decidir e atuar na realidade socioambiental, comprometendo-se com a vida digna em termos ecológicos e sociais, que será possível pela difusão de informações, conceitos e reflexão crítica da ocupação do ambiente, no âmbito dos debates presentes na comunidade escolar com a formação de valores ambientais solidários a todos os seres vivos do planeta.

Assim, a ideia de cidadão crítico não é determinante para inserção na ideia de cidadania socioambiental crítica, isso porque a tomada de decisão precisa estar fora da alienação dos conceitos de Educação Ambiental.

A formação de professores, como educadores ambientais, necessita superar alienação preservacionista (na moda "preserve já"), a alienação da 
conscientização (em verdade, ninguém conscientiza ninguém), alienação comportamentalista (ter bons comportamentos ambientais, como não jogar lixo no chão, não implica necessariamente se apropriar de valores ambientais). As questões referentes ao ambiente crescem em complexidade dada as transformações de mercado num mundo dito globalizado e com muitas inovações tecnológicas. E são essas complexidades que necessitam entrar em debate nas aulas, já que as mesmas têm alterado significativamente o ambiente em que vivemos.

\section{Referências}

BRASIL. Secretaria de Educação Fundamental. Parâmetros curriculares nacionais: terceiro e quarto ciclos: apresentação dos temas transversais / Secretaria de Educação Fundamental. Brasília: MEC/SEF, 436 p, 1998. Disponível em <http://portal.mec.gov.br/seb/arquivos/pdf/ttransversais.pdf>. Acesso em 5 de outubro de 2018.

CARVALHO, I. C. de M. Educação Ambiental: a formação do sujeito ecológico. 3. ed. São Paulo: Cortez, 2008. 256 p.

DIEGUES, A. C. S. O Mito moderno da natureza intocada. São Paulo, Ed. Hucitec, 2004.

FREIRE, P. Pedagogia do Oprimido. $25^{\underline{a}}$ ed. (1 $1^{a}$ edición: 1970). Rio de Janeiro: Paz e Terra, 1998.

GUIMARÃES, M. A dimensão ambiental na educação. 5. ed. São Paulo: Papirus, 2003. $102 \mathrm{p}$.

LEÃO, A. L. C; SILVA, L. M. A. Fazendo Educação Ambiental. 4. ed. rev. atual. Recife: $\mathrm{CPRH}, 1999,32 \mathrm{p}$.

LEFF, E. Discursos Sustentáveis. São Paulo: Cortez, 2010. 293 p.

LOUREIRO, C. F. B. Trajetória e fundamentos da Educação Ambiental. 3. ed. São Paulo: Cortez, 2009. 150 p.

LÜDKE, M; ANDRÉ, M. E. D. A. Pesquisa em Educação: Abordagens Qualitativas. São Paulo: E. P. U, 1986. 99 p.

PARÁ, Universidade do Estado do Pará, Curso de Engenharia Ambiental, Projeto Político Pedagógico, s/d. Disponível em $<$ https://paginas.uepa.br/prograd/index.php/downloads/ppc/ccnt/172-projetopedagogico-curso-engenharia-ambiental.html>. Acesso em 2 de outubro de 2018.

PERES, A. C; SANTANA, A. R. ; FARIAS, L; SILVA, L. P. ; SANTOS, L. B. ; BARROS, M. F. R. ; DANTAS, O. M. S. ; LUZ, P. C. S. ; ARAUJO, R. L. ; PESSOA, W. R. . Fundamentos da Educação Ambiental: Editora da UFPAEDUFPA, 2005. v. 22 
PENTEADO, H. D. Meio ambiente e a formação de professores. 2. ed. São Paulo: Cortez, 1997. 120 p.

SAHEB, D; ASINELLI-LUZ, A. As representações de meio ambiente de professores e alunos e a pedagogia de projetos: um estudo de caso em classes de alfabetização. Rev. eletrônica Mestrado em Educação Ambiental. v.16, janeiro-junho de 2006.

SANTOS, W. L. P. dos; MORTIMER, E. F. Tomada de Decisão para Ação Social responsável no Ensino de Ciências. In: Ciência \& Educação, v.7, n.1, p.95-111, 2001.

SANTOS, W. L. P.; SCHNETZLER, Roseli Pacheco. Ciência e educação para a cidadania. In: CHASSOT, A.I.; OLIVEIRA, R. (Org.). Ciência, ética e cultura na educação. Editora Unisinos. São Leopoldo,1998. p. 255-270.

VIANNA, L. P. De invisíveis a protagonista: Populações tradicionais e unidades de conservação. Ed: Annablume, 2008. 350 p. 